Research Article

\title{
Effect of Aggregate Roughness on Strength and Permeation Characteristics of Lightweight Aggregate Concrete
}

\author{
Ameer A. Hilal \\ Civil Engineering Department, College of Engineering, University of Anbar, Ramadi, Iraq \\ Correspondence should be addressed to Ameer A. Hilal; ameer.hilal@uoanbar.edu.iq
}

Received 28 May 2021; Revised 9 August 2021; Accepted 20 August 2021; Published 29 August 2021

Academic Editor: Chang-Yu Sun

Copyright (c) 2021 Ameer A. Hilal. This is an open access article distributed under the Creative Commons Attribution License, which permits unrestricted use, distribution, and reproduction in any medium, provided the original work is properly cited.

\begin{abstract}
This paper aims to examine the effect of surface roughness of lightweight aggregate particles (LWA) on the strength and permeation characteristics of lightweight aggregate concrete (LWAC). Changing the smooth surface texture of LWA particles was achieved by applying surface polishing to make rough texture of the aggregate particle surface. LWAC mixes with different LWA surface roughness (smooth and rough) were produced, and their strength and permeation properties were investigated. Cut section method was adopted to measure the surface roughness of LWA particles. The surface profile was measured by using ImageJ software on images captured using the optical microscope (OM) and scanning electron microscope (SEM) with different magnifications. The ability of making the surface of LWA particles rough by polishing them was proved by means of $2 \mathrm{D}$ roughness measurements. From the results, it was found that using treated LWA with rough surface helped in enhancing the strength (compressive) and the permeation properties (water absorption and sorptivity) of lightweight aggregate concrete (LWAC). Making the LWA rough helped in improving the compressive strength by about $13.5 \%$ owing to enhancing the ITZ between the LWA particles and the cement paste as well as improving the chemical bonding and mechanical interlocking forces between them. In addition, using rough lightweight aggregate led to reduce the water absorption and cumulative volume of water absorbed by about $9 \%$ and $12 \%$, respectively, compared to values of mix with original (smooth) LWA.
\end{abstract}

\section{Introduction}

Concrete is an extensively used construction material due to availability of its raw materials and its good properties. It can be produced according to its density as light, normal, and heavy weight consisting of three phases: cement paste, aggregate, and the interfacial transition zone (ITZ) between them [1].

The practical density range of lightweight concrete is between $300 \mathrm{~kg} / \mathrm{m}^{3}$ and $1850 \mathrm{~kg} / \mathrm{m}^{3}$. To reduce the total weight of a building with multistorey, a successful approach to follow is using lightweight construction materials. It is well known that, in concrete construction, reducing its weight has an important advantage. Lightweight concrete not only reduced the weight of the building but also provided an excellent thermal and sound insulation and achieved energy conservation benefits. Therefore, enhancing its properties is investigated in this paper. On the other hand, considering the environmental pollution to control and manage waste materials generated by thermal coal-fired power plants, a large amount of fly ash (FA) was used to produce lightweight aggregate (LWA). Production of LWA from FA provides artificial aggregate from recycling waste resulting in reducing the dependence on natural aggregates in concrete industry [2]. Therefore, from growing environmental concern and due to significant advantages of lightweight aggregate, its production should boost in the future. In addition, as the demand for lightweight and thermally insulating construction material increases, LWA market is expected to grow mainly [3,4].

In concrete, such porous LWA particles act as an internal water reservoir with a beneficial effect of supplying curing water internally. During the hydration process, with shortage of water in the cement paste, water transports from the LWA particles to cement paste to support continuous hydration leading to improve 
strength and durability which are associated with lower water-to-cement ratio [5].

It is well known that mechanical behavior and the concrete durability are affected by the interfacial transition zone (ITZ) between the aggregate and the cement paste which to possess these good properties it should be as dense as possible to provide a good bond between the aggregate and matrix $[6,7]$. In general, the ITZ is porous, with a width of 50-100 $\mu \mathrm{m}$, due to formation of large crystalline products in the vicinity of aggregate or the poor packing of cement grains. However, it was reported that the structure of ITZs within the lightweight concrete varies with no definite form [8].

It was stated that, unlike normal aggregate, there is no "wall effect" occurring on lightweight aggregate surfaces, and due to the porous surface of the latter, improvement in the interfacial bond occurred by providing interlocking sites within a dense and uniform ITZ [9].

Many research studies have been carried out to develop or enhance some properties of lightweight aggregate concrete (LWAC) by incorporation of mineral additives [10], use of $\mathrm{CO}_{2}$ curing [11], and adding shrinkage-reducing admixture and fiber reinforcement [12]. However, in this paper, achieving an enhancement in strength and permeation properties of LWAC without using any additives will be investigated. This will be done by changing the smooth surface texture of LWA particles by applying surface polishing to make rough texture of the particle surface. On the other hand, from the production point of view, noticeable problem in the production of concrete using LWA was the phenomenon of aggregates flooding due to aggregate light weight. Therefore, the effect of making the surface more rough on the flooding phenomena will be examined as well.

\section{Experimental Details}

2.1. Materials. Raw materials of lightweight aggregate concrete (LWAC) are cement, water, fine aggregate, and lightweight aggregate (LWA). However, specified admixtures/additives might be used to produce concrete with desired properties. Therefore, to achieve the aim of this paper, LWA with different surface textures (smooth and rough) will be used in this study. The materials used for this paper were type I cement with a specific gravity (S.G.) of 3.15 , original sand with a maximum size of $4.75 \mathrm{~mm}$, and fineness modulus of 2.34 as well as drinkable water. LYTAG lightweight aggregate with spherical shape, $65 \%$ void ratio, 0.9 specific gravity, $1450 \mathrm{~kg} / \mathrm{m}^{3}$ particle density, and particle sizes between 4 and $10 \mathrm{~mm}$ was used as well. Original LWA particles with smooth surface (LWAs) and treated ones with rough surface (LWAr) were used (see Figure 1). Figure 2 shows the sieve analysis of the smooth and rough LWA used. It should be noted here that, to make the surface of original LWA particles rough (Figure 3), these original particles were grinded manually with 120 grit silicon carbide abrasive to make treated LWA particles avoid shape changing and maintain about the same sizes of original particles.

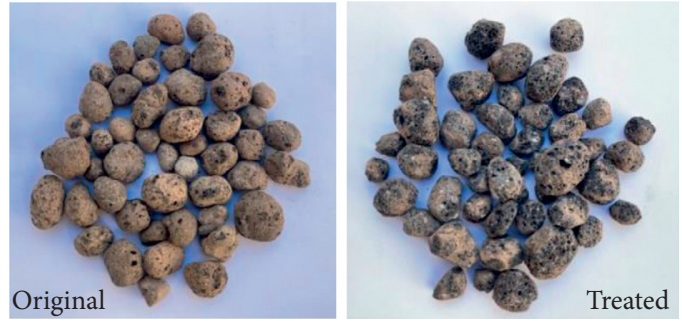

FIGURE 1: Original (smooth surface) and treated (rough surface) lightweight aggregate used.

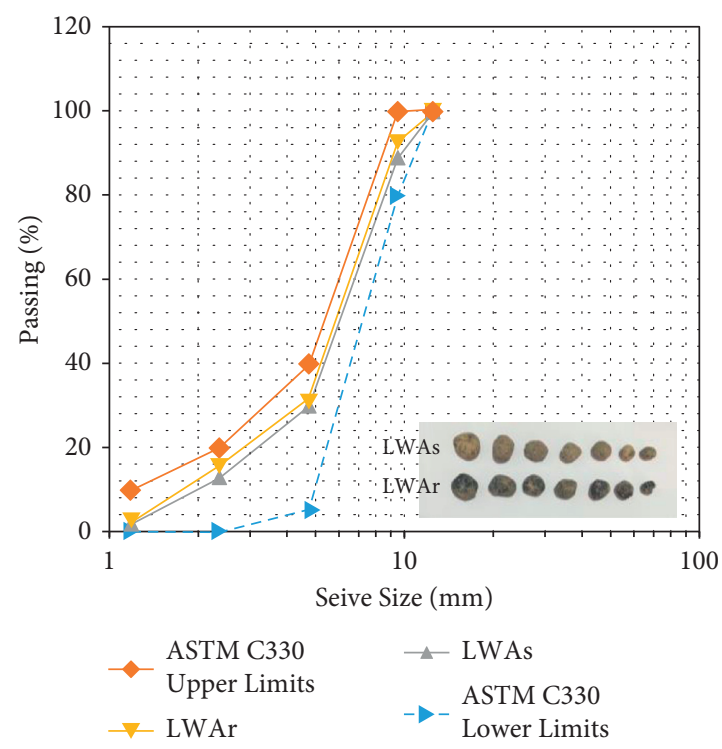

FIGURE 2: Sieve analysis of the smooth (LWAs) and rough (LWAr) lightweight aggregate used.

2.2. Mix Design and Production. In this paper, cement content $\left(400 \mathrm{~kg} / \mathrm{m}^{3}\right)$, sand content $\left(600 \mathrm{~kg} / \mathrm{m}^{3}\right)$, and watercement ratio $(0.5)$ were chosen to start the mix proportioning process. Then, by adopting the absolute volume method and to obtain a target density of $1600 \mathrm{~kg} / \mathrm{m}^{3}$, the LWA content was calculated as $400 \mathrm{~kg} / \mathrm{m}^{3}$.

Production of LWAC is a simple process without the need to any specific machinery, i.e., equipment for the production of conventional concrete can be used. After preparing the predetermined proportions of materials, the mixing process started with adding half of sand, half of cement, all the LWA, and the rest of cement and sand, and then these dry materials were mixed. Then, mixing water was added gradually during the mixing process to produce fresh lightweight aggregate concrete LWAC. Later, the fresh mixture was cast in oiled steel molds and covered with nylon sheets to prevent evaporation of water during the concrete hardening stage. Finally, the specimens with hardened state were removed after 24 hours from casting time and put in water tank for curing until the test day. Figure 4 shows the uniform distribution of LWA particles throughout the specimens. 


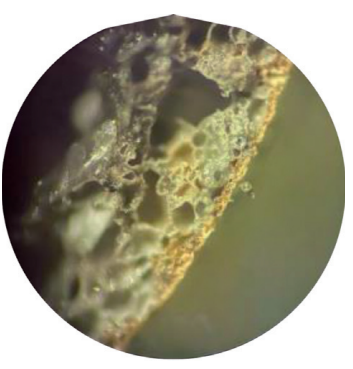

(a)

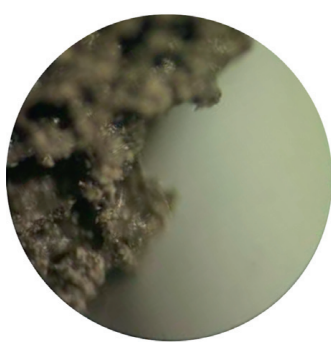

(b)

FIGURE 3: Surface of (a) original (smooth surface) and (b) treated (rough surface) lightweight aggregate used (scale: $5 \mathrm{~mm}$ diameter).

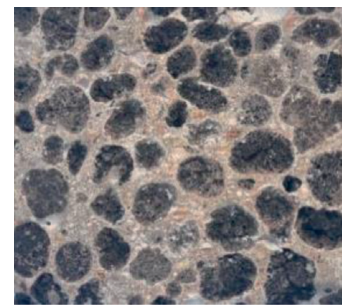

(a)

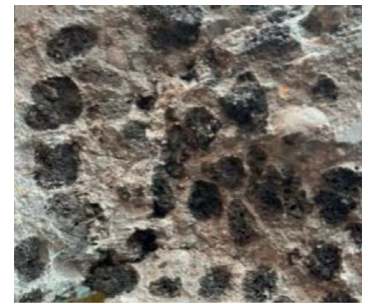

(b)

FIGURE 4: Uniform distribution of LWA particles: (a) LWAs and (b) LWAr (scale: $80 \mathrm{~mm} \times 80 \mathrm{~mm}$ ).

\section{Tests}

3.1. Roughness Measurement. Cut section method was adopted to measure the surface roughness of LWA particles [13]. The cut profile surface of an aggregate particle can be measured after cut, polished, and photographed at the desired level of magnification for concrete specimen. The surface profile is then directly measured by using ImageJ software.

Images captured using an optical microscope (OM) (Figure 5) and scanning electron microscope (SEM) (Figure 6) were used for roughness measurement as $2 \mathrm{D}$ roughness coefficient $\left(R_{C}\right)$. These images were analyzed using ImageJ software to measure the lengths $(L)$ and $(L s)$, equation (1), of LWA particle surface $[13,14]$. Many definitions of aggregate surface roughness have been proposed; however, for this study, the definition adopted for surface roughness $(R c)$ is as follows:

$$
R_{c}=\frac{L}{L_{s}},
$$

where $L$ is the true length of segment of analyzed surface of LWA and $L s$ is the length of best fit line of surface segment.

3.2. Density and Strength. For all investigated mixes, the density $\left(\mathrm{kg} / \mathrm{m}^{3}\right)$ was measured by dividing the weight of specimen $(\mathrm{kg})$ on its volume $\left(\mathrm{m}^{3}\right)$.

Compressive strength test was carried out on $100 \mathrm{~mm}^{3}$ cubes, and the average of three specimens was taken at the ages of 7 and 28 days.

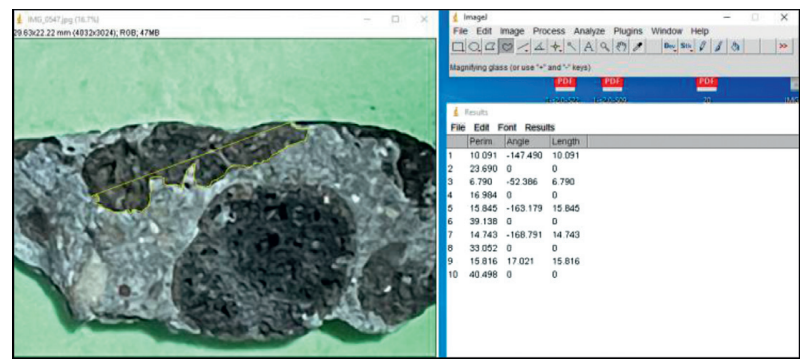

FIGURE 5: Roughness measurement by ImageJ software on the image of optical microscopy (scale: $29 \times 22 \mathrm{~mm}$ ).

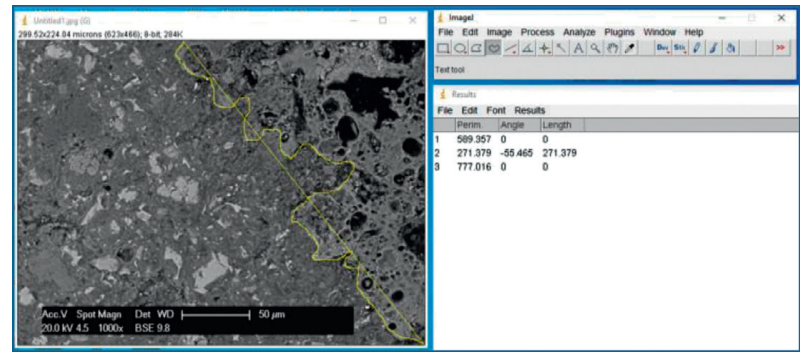

Figure 6: Roughness measurement by ImageJ software on the image of scanning electron microscopy (scale: $299 \times 224$ microns).

\subsection{Permeation Properties}

3.3.1. Water Absorption. Absorption represents a percentage of a mass increase (due to immersing in water and penetrating the concrete with easy manner) to a dry mass to a constant weight [15]. 
This test was carried out at the age of 28 days by measuring the water absorption of three $(48 \times 48 \times 100 \mathrm{~mm})$ wet cured specimens for each mix. The test process was carried out by drying the specimens at $60^{\circ} \mathrm{C}$, until achieving a constant mass, and then immersing them in water for a period of achieving a constant wet mass. The following equation was adopted to measure the water absorption of investigated mixes:

$$
A b=\frac{W_{w}-W_{\mathrm{dry}}}{W_{\mathrm{dry}}} * 100,
$$

where $A b$ is the water absorption value (\%), $W_{w}$ is the wet weight, and $W_{\text {dry }}$ is the dry weight.

3.3.2. Sorptivity. To identify concrete quality and to evaluate its service life, an understanding of its moisture movement is important. Sorption can be expressed as a tendency of concrete to transmit water by capillary suction. This is necessary to indicate the penetration of detrimental solutions such as sulphate and chloride ions, leading to control or prevent long-term deterioration [16].

Movement of water into lightweight concrete can be described as square-root-time relationship [17], as follows:

$$
i=B+S t^{0.5},
$$

where $i$ is water cumulative volume per unit area $\left(\mathrm{mm}^{3} /\right.$ $\mathrm{mm}^{2}$ ) during a time $t(\mathrm{~min})$, while $B$ is an intercept value of $y$-axis at $t=0$ and $S$ is concrete sorptivity obtained from the best fit line of $i$ versus $t^{0.5}$ curve $\left(\mathrm{mm} / \mathrm{min}^{0.5}\right)$.

For sorptivity test, specimens of $100 \mathrm{~mm}^{3}$ sizes were cast and cut for four prisms with dimensions of $48^{*} 48^{*} 95 \mathrm{~mm}$. To remove a mold effect, a slice of about $5 \mathrm{~mm}$ was cut (using a diamond rotary cutter) from the bottom of the surface that will be contacted to water during testing. Then, the specimens were dried at $60^{\circ} \mathrm{C}$ until achieving a constant weight and then left in the laboratory for cooling to room temperature. The lowest $3 \mathrm{~cm}$ of the specimen sides was painted in order to achieve unidirectional flow, see Figure 7. These treated specimens were rested on circular steel bars in a water tray as shown in Figure 7. During the test, the lowest $3 \mathrm{~mm}$ of the sealed sided faces were immerged in a constant level of water to ensure that water will be freely accessed just through the inflow surface. During a test period, 3.5 hours, many weight measurements of submerged specimens were taken to the nearest $0.01 \mathrm{~g}$. This test was carried out at the age of 28 days on two specimens for each mix.

\section{Results and Discussion}

4.1. Roughness Measurement. It was reported that roughness parameter can be used to characterize the surface morphology of aggregate [18]. As observed from the roughness investigation, surface roughness varies greatly over the surfaces of original (smooth) and treated (rough) lightweight aggregate particles. The investigation results demonstrate that, at different observation levels, not only the roughness of the $2 \mathrm{D}$ contour lines of the lightweight

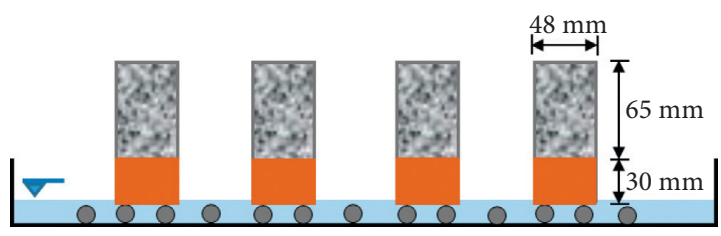

FIGURE 7: Schematic drawing of sorptivity test.

aggregate particles surfaces was different but also the apparent morphologies were quite different (see Figure 8). Observed variations in surface roughness were 1.14 for smooth particles (LWAs) and 1.75 for rough particles (LWAr). These results were the average of 12 readings from SEM images captured at different magnifications and other 12 images captured by an optical microscope.

4.2. Density. Owing to the accuracy in grinding the LWA particles, there was no obvious change in their diameters and the particle distribution of them. This finally contributed, using the same volumes of smooth (original) or rough (treated) LWA particles, in producing LWAC mixes within a density range of $1600 \pm 15 \mathrm{~kg} / \mathrm{m}^{3}$.

4.3. Compressive Strength. Table 1 shows the results of compressive strength of LWAC mixes produced with smooth or rough LWA particles. From the results, for mixes with the same materials proportions, it was found that using rough LWA particles (changing the texture surface) helped in increasing the 28-day compressive strength of LWACr by about $13.5 \%$ compared to that of LWACs with smooth surface of LWA particles. This is may be attributed to the enhancing of bonding between the rough LWA particles and the cement paste leading to increased compressive strength of the mix (see Figure 9). In their study on the effect of coarse aggregate surface texture on mechanical properties of concrete, Jia and $\mathrm{Gu}$ [18] concluded that roughness of aggregate can affect the mechanical properties of the ITZ by not only increasing the actual interface bonding area but also enhancing the mechanical interlocking action between the cement paste and aggregates. It was reported that the bond mechanism between aggregate and cement paste consists of three parts: the van der Waals force (VDW), chemical bonding, and the mechanical interlocking forces [19]. Huang et al. [20] concluded that the bond between rough lightweight aggregate and cement paste was tight, without visible cracks at their interface. For rough surfaces, deposition of cement hydration products in their irregularities resulted in enhancing the mechanical interlocking between the LWA particles and cement paste. Zhao et al. [21] concluded that roughness of aggregate is one of the important parameters having a significance influence on the mechanical properties of concrete. From the microhardness investigation results, it was noticed that the interfacial transition zone (ITZ) between the rough LWAr particles and the cement paste was stronger than that of smooth LWAs particles resulting in making the LWA stronger and hence enhancing the mix strength. This is due to the concentration of the hydrated 

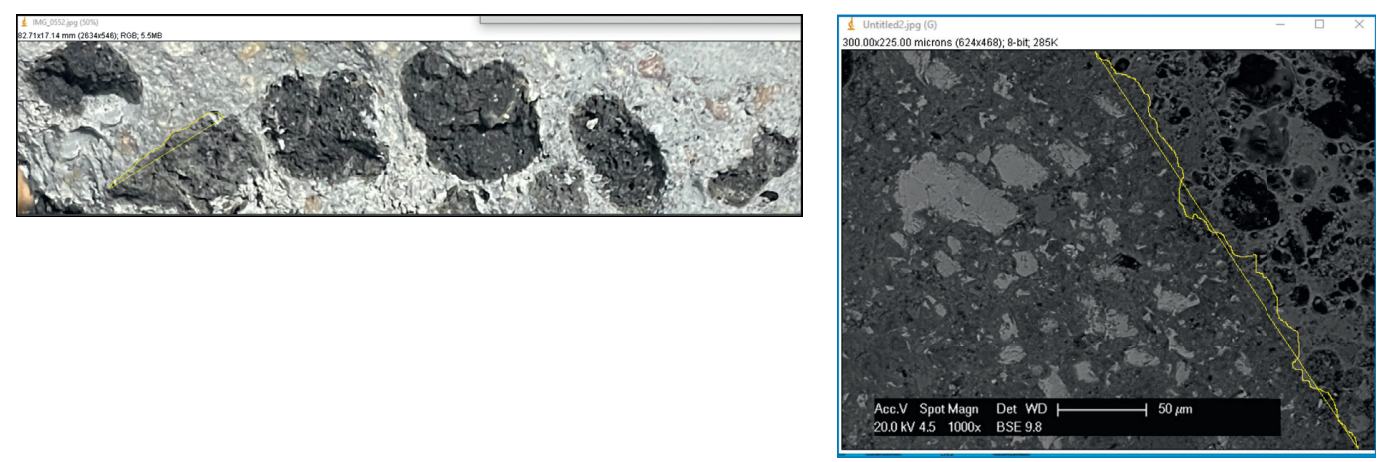

(a)

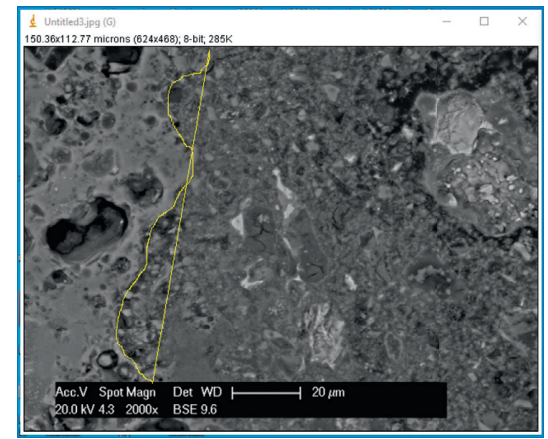

(c) (b)

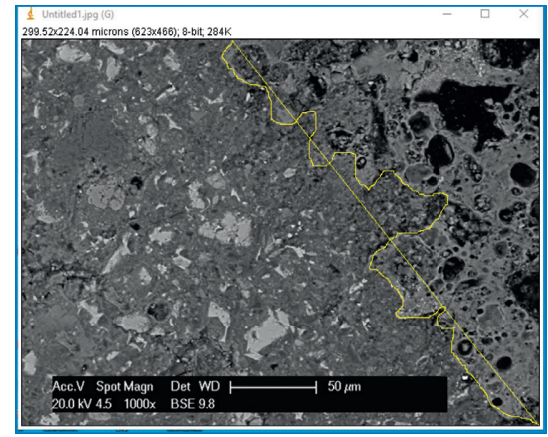

(d)

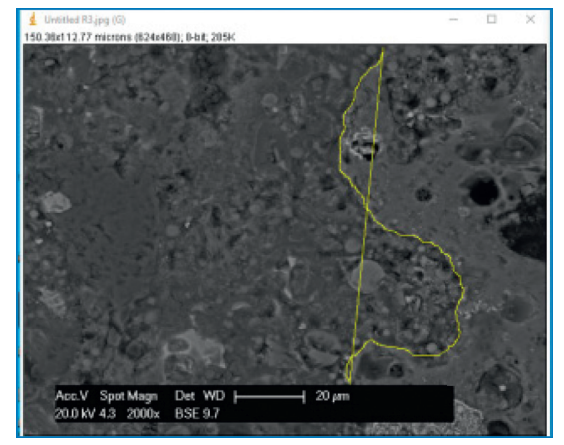

(e)

FIGURE 8: Roughness measurements: (a) optical microscopy image. (b, c) SEM images of LWACs mix. (d, e) SEM images of LWACr mix.

TABLE 1: Compressive strength values at 7 and 28 days.

\begin{tabular}{lcccc}
\hline Mixes & \multicolumn{2}{c}{ LWACs } & LWACr \\
\hline Age (days) & 7 & 28 & 7 & 28 \\
Compressive strength $(\mathrm{MPa})$ & $7.42(0.41)$ & $9.23(0.35)$ & $8.26(0.26)$ & $10.48(0.23)$ \\
\hline
\end{tabular}

Values in ( ) represents standard deviation.

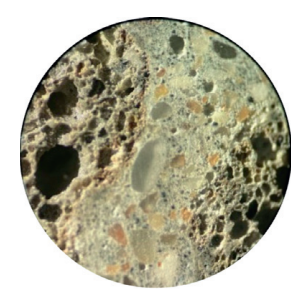

(a)

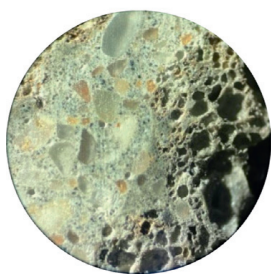

(b)

Figure 9: Interlocking of LWA particles. (a) LWAs and (b) LWAr (scale: $10 \mathrm{~mm}$ diameter). 


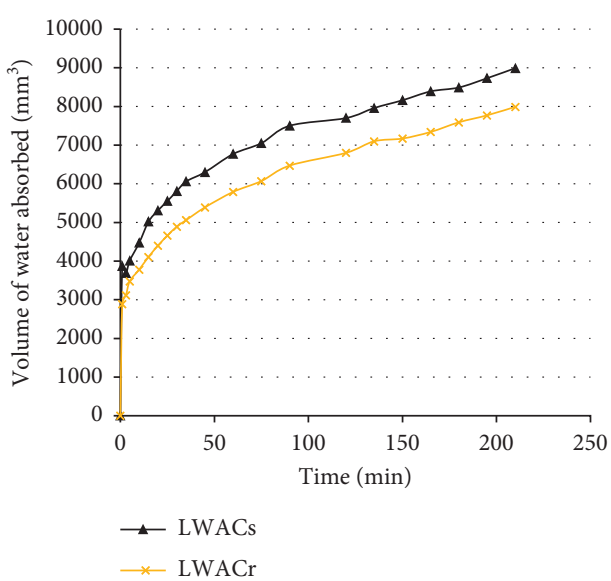

(a)

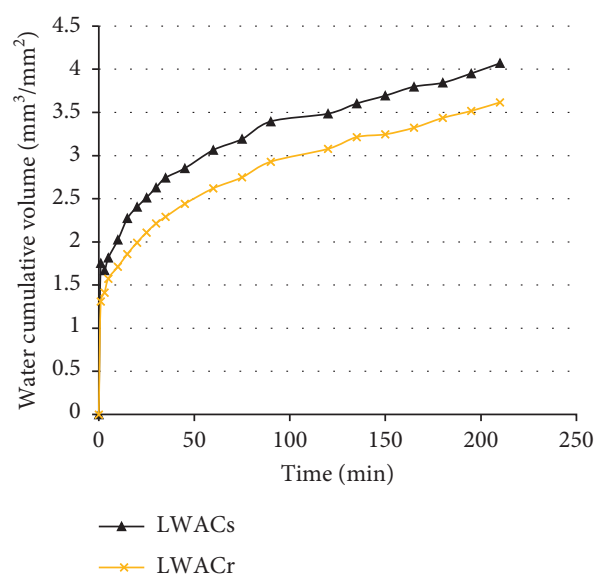

(b)

FIgURE 10: (a) Volume of water absorbed in LWAC mixes versus time and (b) evolution in the cumulative volume of water absorbed in LWAC mixes with time.

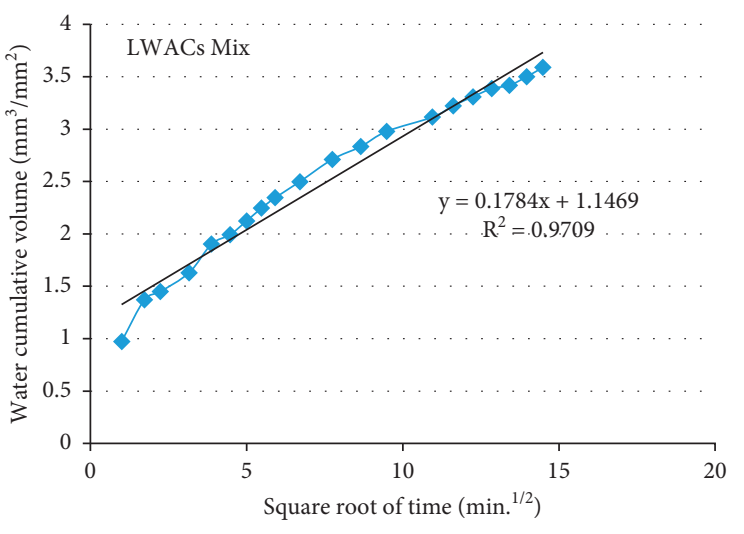

(a)

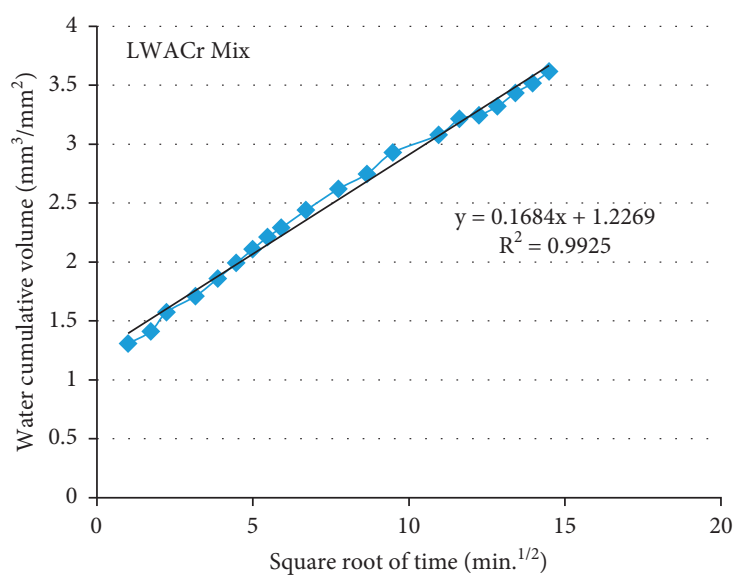

(b)

FIGURE 11: Sorptivity obtained from the $i$ versus $t^{0.5}$ curve using a best fit linear regression (in $\mathrm{mm} / \mathrm{min}^{0.5}$ ) (a) LWACs mix and (b) LWACr mix.

and/or carbonated products near the ITZ mostly on the side of the cement paste [20]. Microhardness investigation was done by using a Vickers microhardness device with the indenter of square-base pyramid, $10 \mathrm{~g}$ test load, and a contact time of $15 \mathrm{sec}$. It was found that ITZ microhardness results (average of five readings) at a distance of $30 \mu \mathrm{m}$ from the surface of LWA particles were 52.4 and $63.1 \mathrm{HV}$ for LWACs and LWACr, respectively (where " $1 \mathrm{HV}=1 \mathrm{kgf}$ / $\mathrm{cm}^{3}=0.09806650 \mathrm{MPa}$ ") [22]. In comparison with normal weight concrete, it was also determined that increasing aggregate surface roughness helped in enhancing concrete compressive $[23,24]$.

\subsection{Permeation Properties}

4.4.1. Water Absorption. It was found that using rough LWAr slightly decreased the water absorption by about $9 \%$ of that of mix with smooth LWAs. This small enhancement indicated that the ITZ around the rough LWAr particles was enhanced noted that the mortar volume was the same in the two investigated mixes (with smooth or rough LWA particles).

4.4.2. Sorptivity. Sorptivity can be characterized as concrete tendency to absorb and transmit water by capillary suction. Therefore, the controlled phase in concrete is its void structure (gel and capillary voids) in cement paste. However, lightweight aggregate itself may contribute to the mechanism of water sorption due to having very fine pores in its cellular structure (Figures (8(b)-8(e)). From the results, it can be seen that due to the enhancement of ITZ around the LWA particles, the LWACr mix with rough LWA particles exhibits less sorptivity (0.168) compared to that with smooth LWAs (0.178) (see Figures 10 and 11 ). In addition, the volume of absorbed water decreased by about $12 \%$ with using rough LWAr in producing lightweight aggregate 
concrete (LWAC). Lyu et al. [25] stated that the ITZ properties are affected by the surface texture of aggregate and the distance of investigated point from the surface of aggregate particle. Unlike the finding of this paper, it was found that because of the effect of packing of cement grains, more porous microstructure in the ITZ was formed around the rough surfaces leading to form a water-rich pocket under the normal aggregate particles resulting in higher water amount in the ITZ region leading to make its microstructure more porous [25]. However, owing to using of porous lightweight aggregate in this investigation, which works as a reservoir for internal curing, the microstructure of ITZ was strong and less porous especially in the case of rough aggregate particles.

\section{Conclusions}

From the experimental investigation and the obtained results, the following conclusions can be drawn:

(1) It is possible to make the texture of lightweight aggregate surface rough by polishing it

(2) Using rough lightweight aggregate resulted in improving the compressive strength by about $13.5 \%$ owing to enhancing the ITZ between the LWA particles and the cement paste as well as improving the chemical bonding and mechanical interlocking forces between them

(3) Using rough lightweight aggregate led to reduce the water absorption and cumulative volume of water absorbed by about $9 \%$ and $12 \%$, respectively, compared to that of mix with original (smooth) LWA. This makes the sorptivity value of mix with rough LWA less than that with smooth LWA.

In general, making the surface of LWA rough helped in enhancing the compressive strength and the permeation properties of lightweight aggregate concrete (LWAC) produced with the same mortar volume.

This study has suggested a number of avenues for future research including the following:

(1) Develop a mechanical method to polish the LWA surface rather than the manual way

(2) Investigate the effect of LWA grading on properties of LWAC

(3) Adding some additives such as fly ash and silica fume by different ways to investigate their effect on LWAC made with rough or smooth LWA

\section{Data Availability}

All data are fully provided in the results section of this paper.

\section{Disclosure}

This research was performed as part the author employment as teaching member at University of Anbar/Iraq.

\section{Conflicts of Interest}

The author declares that there are no conflicts of interest regarding the publication of this article.

\section{References}

[1] T. Akçaoğlu, M. Tokyay, and T. Çelik, "Effect of coarse aggregate size and matrix quality on ITZ and failure behavior of concrete under uniaxial compression," Cement and Concrete Composites, vol. 26, no. 6, pp. 633-638, 2004.

[2] E. Güneyisi, M. Gesoglu, O. A. Azez, and H. Ö. Öz, "Effect of nano silica on the workability of self-compacting concretes having untreated and surface treated lightweight aggregates," Construction and Building Materials, vol. 115, pp. 371-380, 2016.

[3] A. Wongsa, V. Sata, P. Nuaklong, and P. Chindaprasirt, "Use of crushed clay brick and pumice aggregates in lightweight geopolymer concrete," Construction and Building Materials, vol. 188, pp. 1025-1034, 2018.

[4] J. M. Moreno-Maroto, M. Uceda-Rodríguez, C. J. CoboCeacero, T. Cotes-Palomino, C. Martínez-García, and J. Alonso-Azcárate, "Studying the feasibility of a selection of Southern European ceramic clays for the production of lightweight aggregates," Construction and Building Materials, vol. 237, Article ID 117583, 2020.

[5] J. Castro, L. Keiser, M. Golias, and J. Weiss, “Absorption and desorption properties of fine lightweight aggregate for application to internally cured concrete mixtures," Cement and Concrete Composites, vol. 33, no. 10, pp. 1001-1008, 2011.

[6] N. M. Mhedi, A. A. Hilal, and A.-H. Abdulkader, "Re-use of waste plastic as fibers in production of modified foamed concrete," in Proceedings of the 11th International Conference On Developments In eSystems Engineering (DeSE), pp. 295299, Cambridge, UK, September 2018.

[7] M.-H. Zhang and O. E. Gjørv, "Microstructure of the interfacial zone between lightweight aggregate and cement paste," Cement and Concrete Research, vol. 20, no. 4, pp. 610-618, 1990.

[8] D. Breton, A. Carles-Gibergues, G. Ballivy, and J. Grandet, "Contribution to the formation mechanism of the transition zone between rock-cement paste," Cement and Concrete Research, vol. 23, no. 2, pp. 335-346, 1993.

[9] T. Y. Lo and H. Z. Cui, "Effect of porous lightweight aggregate on strength of concrete," Materials Letters, vol. 58, no. 6, pp. 916-919, 2004.

[10] Z. Y. Qu and Q. L. Yu, "Synthesizing super-hydrophobic ground granulated blast furnace slag to enhance the transport property of lightweight aggregate concrete," Construction and Building Materials, vol. 191, pp. 176-186, 2018.

[11] P. Tang, D. Xuan, H. W. Cheng, C. S. Poon, and D. C. W. Tsang, "Use of $\mathrm{CO} 2$ curing to enhance the properties of cold bonded lightweight aggregates (CBLAs) produced with concrete slurry waste (CSW) and fine incineration bottom ash (IBA)," Journal of Hazardous Materials, vol. 381, Article ID 120951, 2020.

[12] E. Güneyisi, M. Gesoğlu, A. Mohamadameen, R. Alzeebaree, Z. Algın, and K. Mermerdaş, "Enhancement of shrinkage behavior of lightweight aggregate concretes by shrinkage reducing admixture and fiber reinforcement," Construction and Building Materials, vol. 54, pp. 91-98, 2014.

[13] R. D. Barksdale, M. A. Kemp, W. J. Sheffield, and J. L. Hubbard, "Measurement of aggregate shape, surface area, 
and roughness," Transportation Research Record, vol. 1301, pp. 107-116, 1991.

[14] L. Li, M. Guo, and C. Zeng, "Study on the accurate measurement and quantitative evaluation methods of aggregate surface roughness," Annals of Materials Science \& Engineering, vol. 2021, Article ID 6611691, 12 pages, 2021.

[15] A. A. Hilal, N. H. Thom, and A. R. Dawson, "Pore structure and permeation characteristics of foamed concrete," Journal of Advanced Concrete Technology, vol. 12, no. 12, 2014.

[16] E. K. K. Nambiar and K. Ramamurthy, "Sorption characteristics of foam concrete," Cement and Concrete Research, vol. 37, no. 9, pp. 1341-1347, 2007.

[17] T. Y. Lo, H. Z. Cui, A. Nadeem, and Z. G. Li, "The effects of air content on permeability of lightweight concrete," Cement and Concrete Research, vol. 36, no. 10, pp. 1874-1878, 2006.

[18] J.-Y. Jia and X.-L. Gu, "Effects of coarse aggregate surface morphology on aggregate-mortar interface strength and mechanical properties of concrete," Construction and Building Materials, vol. 294, Article ID 123515, 2021.

[19] L. Zhang, Y. Zhang, C. Liu, L. Liu, and K. Tang, "Study on microstructure and bond strength of interfacial transition zone between cement paste and high-performance lightweight aggregates prepared from ferrochromium slag," Construction and Building Materials, vol. 142, pp. 31-41, 2017.

[20] H. Huang, Y. Yuan, W. Zhang, B. Liu, A. Viani, and P. Mácová, "Microstructure investigation of the interface between lightweight concrete and normal-weight concrete," Materials Today Communications, vol. 21, Article ID 100640, 2019.

[21] Y. Zhao, Y. Duan, L. Zhu, Y. Wang, and Z. Jin, "Characterization of coarse aggregate morphology and its effect on rheological and mechanical properties of fresh concrete," Construction and Building Materials, vol. 286, Article ID 122940, 2021.

[22] A. A. Hilal, N. H. Thorn, and A. R. Dawson, "Failure mechanism of foamed concrete made with/without additives and lightweight aggregate," Journal of Advanced Concrete Technology, vol. 14, no. 9, 2016.

[23] K. Güçlüer, "Investigation of the effects of aggregate textural properties on compressive strength (CS) and ultrasonic pulse velocity (UPV) of concrete," Journal of Building Engineering, vol. 27, Article ID 100949, 2020.

[24] X. Zhou, Y. Xie, G. Long, and J. Li, "Effect of surface characteristics of aggregates on the compressive damage of highstrength concrete based on 3D discrete element method," Construction and Building Materials, vol. 301, Article ID 124101, 2021.

[25] K. Lyu, E. J. Garboczi, W. She, and C. Miao, "The effect of rough vs. smooth aggregate surfaces on the characteristics of the interfacial transition zone," Cement and Concrete Composites, vol. 99, pp. 49-61, 2019. 